\title{
IMPACT OF AN EVIDENCE-BASED EDUCATIONAL PROGRAM ABOUT PEDIATRIC OPEN HEART SURGERY CARE ON BOTH NURSES AND PATIENTS' OUTCOMES ${ }^{1}$ Wagnat Mohamed EL- Razky, ${ }^{2}$ Fawzia El-Sayed Abusaad, ${ }^{3}$ Rabab EL-Sayed Hassan and ${ }^{4}$ Sahar Farouk Hashem \\ 2, 3, \& ${ }^{4}$ Pediatric Nursing Department, Faculty of Nursing, Mansoura University. E-mail of corresponding author: Wagnatm@jmail.com
}

\begin{abstract}
:
Open heart surgery (OHS), operations performed on the heart that require a child being placed on the heart-lung bypass machine. It is a common surgical procedure that can save lives and improve the quality of heart. Open heart surgery better treatable way of congenital heart disease and needs special care. Cardiothoracic surgical nurses key role in improving quality of children care through management of children to achieve optimal outcomes and prevents complications of open heart surgery. Aim: Evaluate the impact of an evidencebased educational program about pediatric open heart surgery care on both nurses and patient's outcomes. Methods: Quasi-experimental design for one group was utilized in carrying out the study at the Pediatric cardiology units at Mansoura University Children's Hospital and Institute of Heart in Damietta, on a sample of 40 nurses and 106 children undergoing open heart surgery for the first time, children in the age group from birth to 5 years, for at least 3 months. Data were collected by using three tools: Characteristics of studied nurses, structured interview questionnaire, nurses knowledge, nurses' reported practices regarding care of pediatric patient, and caregiver satisfaction scale Results: nurses' knowledge about congenital heart diseases and open heart surgery in pediatric is generally low, reported practice of the nurses had an incompetent before conducting the program, while it improved to become competent and their practice of postoperative care for open heart surgery is unsatisfactory. While immediately after and follow-up the implementation of educational program significant improvements in nurses' knowledge and practice was observed; all the areas were adequately performed by almost all nurses for almost all children in the study group. This is a positively reflected on child's outcomes Conclusion: The implementation of the educational program regarding care pre, immediate and follow up of children with OHS had a positive effect on the improvements of nurses' knowledge, practice and nurses' satisfaction. In addition, there were statistical significant differences between nurses' knowledge and practice pre immediate and follow up the program were observed Recommendations: Regular and continuous educational programs for cardio surgical nurses are essential for improving their knowledge and practice about children' with open heart surgery. Keywords: Evidence based practice, Congenital heart disease, Open heart surgery, Educational program, Nurses, and Patient's outcomes
\end{abstract}

\section{Introduction:}

Congenital heart disease can describe a wide variety and different abnormalities affecting the heart. The incidence of congenital heart disease in children in Egypt, approximately 78 per 1000 live births. About 2 to3 in 1000 infants will be 
symptomatic during the first year of life (Linde et al. 2011). Congenital heart disease is the main reason of death in the first year of life, CHD account for nearly one-third of all major congenital anomalies (AHA, 2015 and Michael et al. 2015).

Congenital heart disease usually presents in infancy as cyanosis or heart failure or a combination of both, presence of heart murmur, circulatory shock, stridor, hypercyanotic spells and growth failure (National Database Brochure, 2017). It is vital for the diagnosis of CHD to obtain exact history and physical assessment of the child. Variety of analytic procedures and tests are summarized in laboratory investigation, thoracic radiograph, electrocardiography, echocardiography, cardiac catheterization, angiography and magnetic resonance imaging (MRI) (Walsh, 2010).

Health care system requires to apply intervention that not only increase nurses' Evidence Based Nursing Practice (EBP) knowledge and skills, but also reinforce their beliefs about the benefits of evidence-based care. Evidence Based Nursing Practice ( EBNP) aid in care of children undergoing OHS that get better health of children; reduce mortality, complications and duration of stay in hospital. Evidence-based practice is conscientious and well judged utility of up to date best evidence in combination with clinical expertise and patient principles to lead health care decision (Titler, 2011).

The majority of pediatric heart procedures are open heart surgery (OHS). It is a common surgical process that can maintain life; develop performance of heart that is working abnormally (Kurt et al. 2013). Heart diseases are representing a foremost health problem amongst Egyptian children (Park, 2014).

The main goal of pre-operative nursing care is to place the child in the greatest potential condition for surgery throughout careful assessment and during preparation. The preoperative nursing diagnoses provide the basis for consistent, holistic care from admission through recovery (Neirotti, 2013). The nurse determines the child's physical condition and prepares him physically for surgery. Assess the child's diagnosis and the planned surgery to determine what care will be needed and what complications might be expected (Hawk, 2013).

Traditionally, children who undergo open heart surgery have been considered as being critically ill and must remain in intensive care for 24-48 hours postoperatively (Cavalcante et al. 2014). Original postoperative care focuses on achieving and maintaining stability of hemodynamics and improvement after general anesthesia (Craven et al. 2013).

Health care systems needs applying intervention through broaden nurses' support based perform skills and practices and also reinforce their values concerning reimbursement of evidence-based care (Titler, 2011). Nursing role during postoperative period is extremely essential for child's recovery. Immediate postoperative goals include maintenance of adequate ventilation, oxygenation and hemodynamic stability (Hawk, 2013).

Nursing care during this period includes monitoring the patient's cardiovascular status, ventilator parameters, fluid balance and neurological status and prepared pediatric patients to calm, safety and encourage early mobility to avoid complications. Pediatric intensive care nurses play a vital role in the prevention or decreasing complications of OHS (Ahmed, 2012 and Azer et al. 2014).

Pediatric cardiology nurse is a chief member of cardiology team; act as a link to improve her contact with the cardiology team. Major attention must focus on nurses' knowledge and practice regarding care of post-operative OHS because nurses 
IMPACT OF AN EVIDENCE-BASED EDUCATIONAL etc...

have the major responsibilities to reduce the incidence of the complications and support the child and her / his family and provide teaching related to definite procedures and post- operative care (Larry et al. 2014).

The pediatric nurses must apply the most up-to-date, research-tested information to improve their practical skills that reflect their way on providing care for OHS children that improve children's' health and consequently better quality of life (Titler, 2011).

\section{Aim of the study:}

The aim of the study was to evaluate the impact of an evidencebased educational program about pediatric open heart surgery care on nurses' knowledge, practices and satisfaction.

\section{Research hypothesis:}

- Nurses will have better knowledge, practice \& will be more satisfied regarding care of children with open heart surgery after implementation of evidence-based educational program.

- Operative outcomes of pediatric children will be better (decrease length of stay, complications) among open heart surgery children after implementation of evidencebased educational program.

\section{Materials and Methods}

\section{I- Materials:}

Design:

A quasi-experimental research design was utilized in this study.

Setting:

This study was carried out at Pediatric cardiology units at Mansoura University Children's Hospital and Institute of Heart in Damietta, Egypt.

\section{Subjects:}

The subjects of the study included A convenience sample of (40) nurses working at the above mentioned setting and providing care for children with open heart surgery and a purposive sample of 106 pediatric patients with open heart surgery.

Tools:

Tool (1): Child's Assessment Sheet: (pre \&post format)

It was developed by Elsie \& Marvin (2009), and translated into Arabic language by the researcher to gather information about the medical condition of the pediatric patient. This tool consists of 21 questions that covered characteristics of studied patient, medical history of the child preoperative assessment, physiological measurements such as vital signs and lab investigations and Post operative outcomes.

Tool II: questionnaire to assess the nurses' knowledge about pediatric open heart surgery; this tool was adapted from Aziz \& Younis (2013). Questions were in the form of multiple choice questions. This tool was used pre and post program implementation. It included two parts as the following:

Part I: Socio-demographic data of nurses including: age, level of education, years of experience and previous attendance of training program related caring of pediatric patient with open heart surgery in PCICU.

Part II: Concerned with nurses' knowledge about congenital heart disease and open heart surgeries such as: definition, causes, manifestations, complications, pre, intra and postoperative nursing care for children undergoing open heart surgery.

Part (III:) Concerned with nurses reported practices regarding care given for children with open heart surgery such as: infection control measures, pain, nutritional, renal and respiratory assessment, exercise performance, drug administration and chest tube drainage assessment.

Tool: (III) A- Observation checklist for nurse's performance regarding care of children with open 
heart surgery, This tool was designed in English language based on review of pertinent literature (American Heart Association, 2008), to assess nurses' performance regarding postoperative management of children undergoing cardiac surgery. It assessed various tasks as regard child assessment on immediate ICU admission, care of child on ventilator, mobility exercises, suctioning technique, coughing and breathing exercises \& removal of chest tube, maintaining intravenous infusion, providing urinary catheter care and removing it.

B- As regard wound care observational checklist, it was adopted from Bates-Jensen Wound Assessment Tool (BWAT, 2010) The Bates-Jensen wound assessment tool (BWAT) is a standardized tool designed for easy assessment, meaningful communication. Tracking of wounds, in order to use the tool, nurses must have a working knowledge of wound vocabulary and wound-assessment skills. Because many nurses are visual learners, the authors decided to create a visual method of training nurses in the use of the BWAT. Which includes (13 items) to assess wound size, depth, edges, amount of necrotic tissues, type and amount of exudates, surrounding skin color, edema and its duration. It was rated by using a modified Likert scale; a score of (1) indicates the healthiest wound and (4) indicates the unhealthiest wound attribute for each characteristics.

C- Pain relieve observational checklist, it was adopted from Wong-Baker pain rating scale ( 2009), it shows a series of faces ranging from a happy face at $(0)$, "no hurt" to a crying face at (10) "hurts worst". Tool (1V): Caregiver Satisfaction Scale: Caregiver satisfaction questionnaire (CSQ): was adapted from Morsy, (2000). The participants answered the questions using the Likert scale (1-4), in which the options differed according to the type of question. likert scale is applied to assess nurses' job satisfaction and in our research, some modifications are used to serve the aim of the research and translated into Arabic language by the researcher. It contained (25) items that cover the six aspects of care such as: technical quality (5 items unit (6 items), communication and time with the doctor (7 items), haw to deal with employee of the), financial aspects of care (4 items) and acceptance of care (3 items).

The educational program to improve the nurses' knowledge, practices, and satisfaction about nursing care of children with open heart surgery in cardiology units.

The investigator designed the educational program based on the actual need assessment of the studied nurses through reviewing the related literature. The training program was containing the theoretical and practical skills. The training program aims to improve the nurses' knowledge, practices, as well as their satisfaction about nursing care of children with open heart surgery.

Nurses were divided into small groups; (3-4 in each group). The program was given in eight sessions; four theoretical and four practical sessions (around 30-45 minutes for each). Various teaching methods were used in the form of lectures, group discussion, demonstration and re-demonstrations. Various teaching media were used, such as colored posters, power point, video and hand out.

Nurses' knowledge, practice and satisfaction were evaluated three times pre / immediate post and three months later after implementation of the training program using the previously mentioned study tools.

\section{Method:}

An official permission was obtained by submission of an official letter to the director of the hospital and the head of Pediatric Intensive Care Unit to conduct 
IMPACT OF AN EVIDENCE-BASED EDUCATIONAL etc...

the study after explaining the aim of the study. The tools were developed by the researcher, after reviewing of the related literature.

The developed tool was submitted to a jury of five experts in the pediatric nursing field for its content validity. Based on their comments; necessary modifications were done. The reliability of the tool was done by measuring the internal consistency of its items using the Alpha Cronbach's coefficient.

Data collection of this study was carried out over four month's period that started from $1^{\text {st }}$ January 2017 to the end of April 2017.

A pilot study was carried out on $10 \%$ of the participants in order to assess the feasibility, clarity and applicability of the tool. Minor modification were done accordingly, estimate the time needed to complete the questionnaire, and to added or omit questions. That sample of pediatric patient will be excluded from the total of study sample. Nurses whose taken during pilot study were included in the study.

\section{Ethical Considerations}

Ethical approval was obtained from Research Ethics Committee at the Faculty of Nursing - Mansoura University. Confidentiality of data and anonymity as well as nurses' right to withdraw from the study at any time was ascertained.

\section{Data Analysis}

The collected data were coded and entered in a data based file using the excel program for windows. Frequency analysis and manual revision were used to detect any error. After complete entry, data were transformed to the statistical package of social sciences (SPSS) version 18 by which the analysis was conducted applying frequency tables with percentages. Data were revised, coded and analyzed. All tests were performed at a level of significance of $5 \%(\mathrm{P}<0.05)$.
Results:

figure (1). Concerning the years nurses' experience working at cardiology intensive care units, the current study showed that, one third $33 \%$ of nurses had from 1> 3 years of working as a specialist at nursing care of cardiac pediatric patient.

As regards the studied nurses' training course through working at pediatric cardiology intensive care units, figure 2 illustrated that, one quarter $25 \%$ of them received one course taken two courses and the same percentage were taken three courses.

Table (1), illustrates total level of nurses' knowledge of the studied nurses about $\mathrm{CHD}$, OHS and reported practices before / immediately after and follow-up after 3 months of program implementation (77.3\%, $75.8 \%$ and $94.3 \%$ respectively) had "poor" level of knowledge of the studied nurses about CHD, OHS and reported practices before the program implementation, this percent improved in which the majority $(85.8 \%, 93.4 \%$ and $81.1 \%$ ) had 'good" level knowledge immediately the program implementation respectively. While after 3 months of the program this percent decreased. There were statistically significant differences between total levels of nurses' knowledge before, immediately and after 3 months later $\mathrm{P}>0.05$

The mean scores of nurses' practices about care of CHD, and OHS were illustrated in table (2). It is revealed from this table that, the majority $(87.5 \%)$ of the studied nurses had an incompetent practice score before conducting the program, while it improved to become $90 \%$, and 77.5\% competent practices immediately after the program and at follow up respectively. The same table also cleared that, there were statistically significant differences between before and immediately after 
the program as well as between before and at follow up phase of the program implementation at $\mathrm{p}=0.000$.

Regarding postoperative outcomes among children after implementation of educational program, it was found from table (3) that, there were obvious improvements, depth, rhythm and breathes sound of respiration from first and sex days post operatively.

Figure (3) Percentage distribution for pediatric patient according to their post-operative length of stay at PCICU $(n=106)$, as regards the studied pediatric patient's length of stay in PCICU after open-heart surgery, this figure illustrated that, nearly half $(48.5 \%)$ of them were stayed from one to four days. While, (26.6\%) and $(9.3 \%)$ of them stayed from four days to less than one week and $(15.6 \%)$ of them stayed more than one week.

Figure (4); presents level of nurses' satisfaction in care of child with OHS in pediatric cardiology unit. It was shown from the table that more than half of nurses $57.5 \%$ were unsatisfied within care of child with open heart surgery in PCICU, compared to more than two fifth $42.5 \%$ of them respectively were satisfied care of child with open heart surgery at PCICU before \& post the program

Figure (1): Percentage Distribution of the Studied Nurses according to years of experiences working at PCICU.

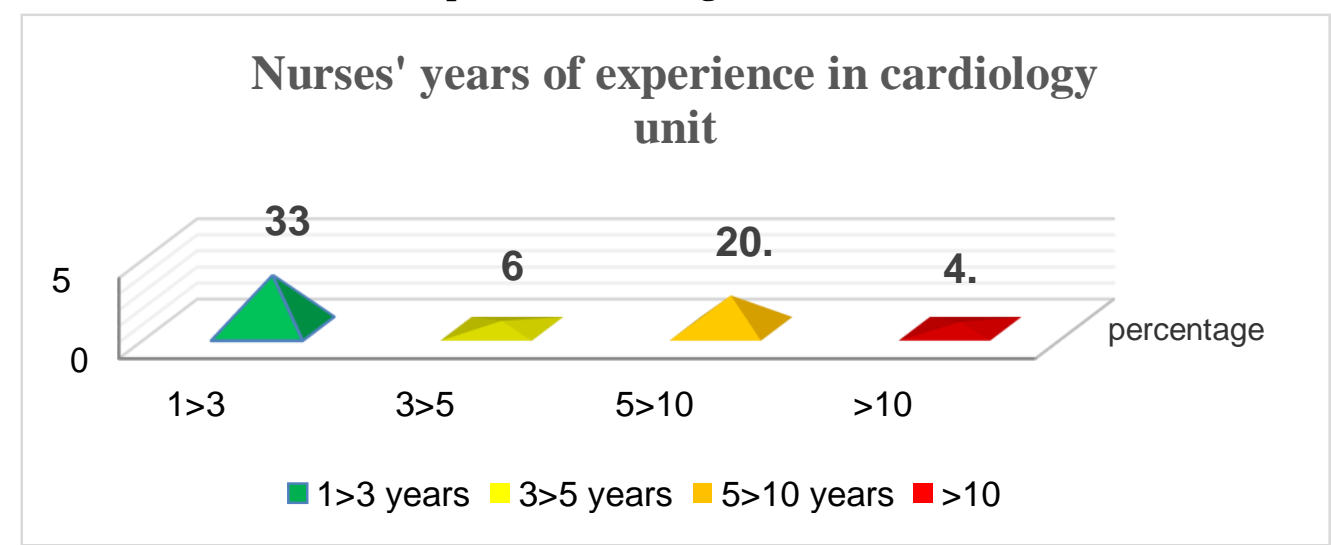

Figure (2): Percentage Distribution of the Studied Nurses According to their Course Training taken at PCICU.

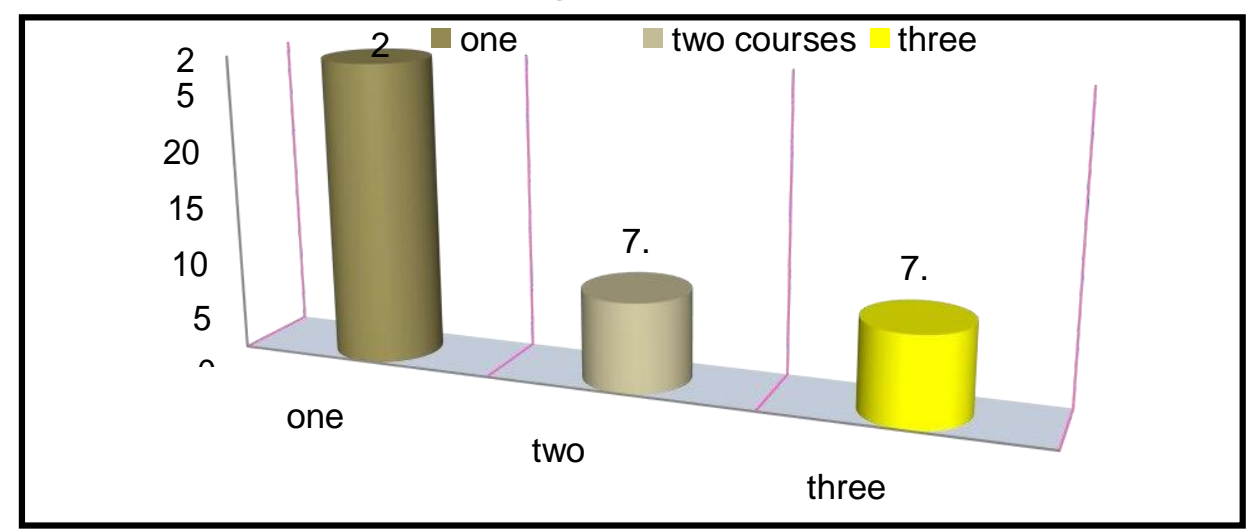




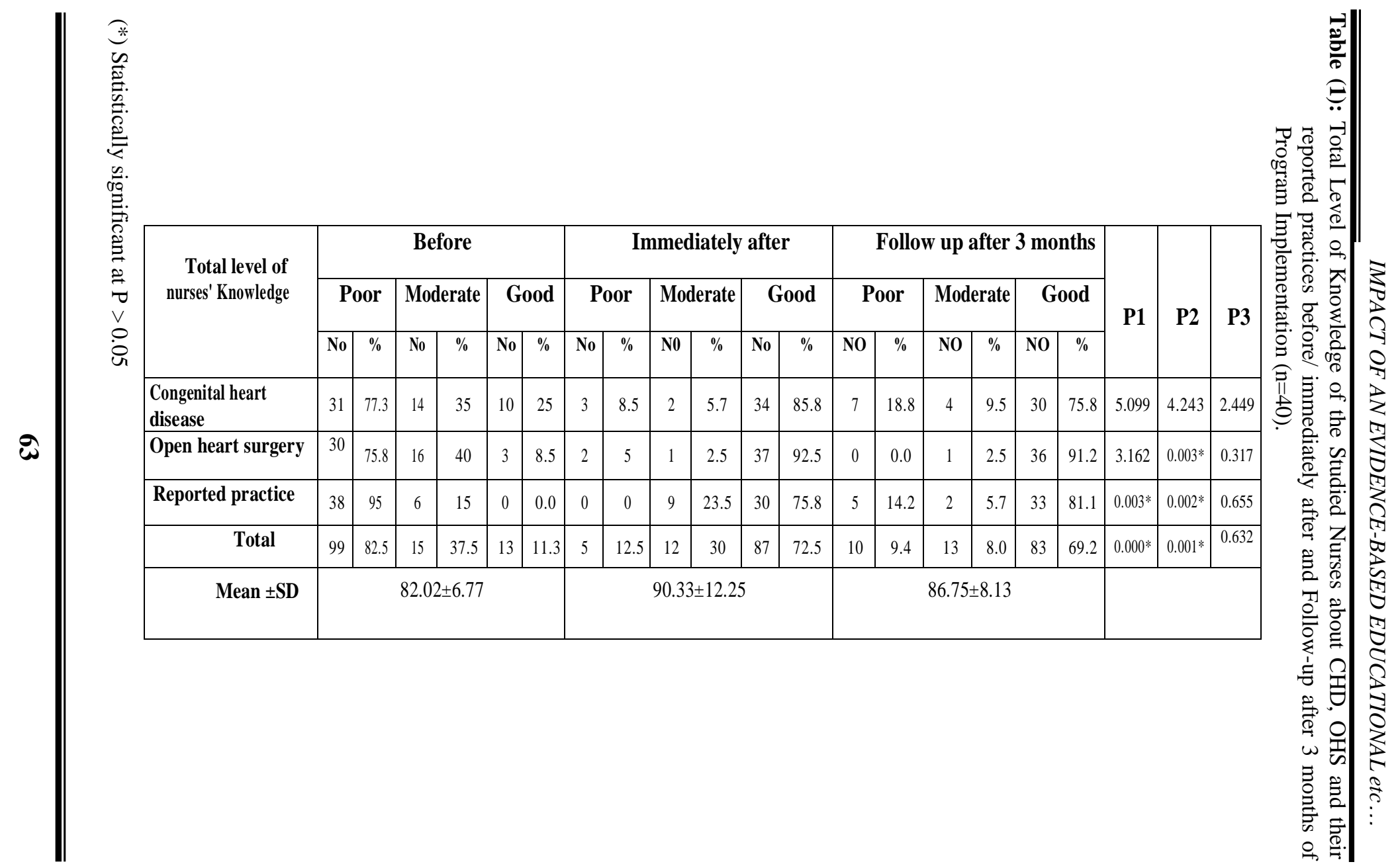


Wagnat Mohamed EL-Razky et. al.

Table (2): Number and Percentage Distribution of Nurses' Practice level before implementation of the study program, immediately after, and at follow up after 3 months. $n=(40)$

\begin{tabular}{|c|c|c|c|c|c|c|c|c|}
\hline \multirow[t]{2}{*}{$\begin{array}{c}\text { Total Nurses' } \\
\text { Practice }\end{array}$} & \multicolumn{2}{|c|}{ Before } & \multicolumn{2}{|c|}{$\begin{array}{c}\text { Immediately } \\
\text { after }\end{array}$} & \multicolumn{2}{|c|}{$\begin{array}{c}\text { Follow up } \\
\text { after } 3 \\
\text { months } \\
\end{array}$} & \multicolumn{2}{|c|}{$\begin{array}{l}\text { Test of } \\
\text { significance }\end{array}$} \\
\hline & No & $\%$ & No & $\%$ & No & $\%$ & Z\&p1 & Z\&p2 \\
\hline Incompetent & 35 & 87.5 & 4 & 10 & 8 & 20 & 6.881 & 5.296 \\
\hline Competent & 5 & 12.5 & 36 & 90 & 40 & 77.5 & & \\
\hline
\end{tabular}

(*) Statistically significant at $\mathrm{P}>0.05$

Z\& p1=differences between before \& immediately after $\quad$ Z\& p2=differences between before \& follow up.

\section{Pediatric Patient Outcomes after Open Heart Surgery}

Table (3): Distribution of Pediatric Patient Assessment Regarding to Depth, Rhythm of Respiration and Breath Sound post Open Heart Surgery. $n=106$

\begin{tabular}{|c|c|c|c|c|c|c|c|c|c|c|c|c|}
\hline \multirow{3}{*}{ Item } & \multicolumn{2}{|c|}{$1^{\text {st }}$ day } & \multicolumn{2}{|c|}{$2^{\text {nd }}$ day } & \multicolumn{2}{|c|}{3 day } & \multicolumn{2}{|c|}{$4^{\text {th }}$ day } & \multicolumn{2}{|c|}{$5^{\text {st }}$ day } & \multicolumn{2}{|c|}{$6^{\text {th }}$ day } \\
\hline & \multicolumn{2}{|c|}{$\begin{array}{c}\text { Immediatel } \\
\text { y Post }\end{array}$} & \multicolumn{2}{|c|}{$\begin{array}{c}\text { Immediatel } \\
\text { y post }\end{array}$} & \multicolumn{2}{|c|}{$\begin{array}{c}\text { Immediately } \\
\text { Post }\end{array}$} & \multicolumn{2}{|c|}{$\begin{array}{c}\text { Immediately } \\
\text { Post }\end{array}$} & \multicolumn{2}{|c|}{$\begin{array}{c}\text { Immediatel } \\
\text { y Post }\end{array}$} & \multicolumn{2}{|c|}{$\begin{array}{c}\text { Immediately } \\
\text { Post }\end{array}$} \\
\hline & No & $\%$ & No & $\%$ & No & $\%$ & No & $\%$ & No & $\%$ & No & $\%$ \\
\hline \multicolumn{13}{|l|}{$\begin{array}{c}\checkmark \text { Depth of } \\
\text { respira } \\
\text { tion: }\end{array}$} \\
\hline - Deep & 31 & 29.2 & 33 & 31.1 & 69 & 65.1 & 100 & 94.3 & 101 & $\begin{array}{c}95 . \\
2\end{array}$ & 100 & 94.3 \\
\hline Shallow & 75 & 70.8 & 73 & 68.9 & 37 & 34.9 & 6 & 5.6 & 5 & 4.7 & 6 & 5.6 \\
\hline \multicolumn{7}{|c|}{$\mathrm{X} 2=0.41$} & \multicolumn{6}{|c|}{$P$ value $=0.03^{*}$} \\
\hline \multicolumn{13}{|l|}{$\begin{array}{ll}\checkmark & \text { Rhyt } \\
\text { hm } \\
\text { of } \\
\text { respi } \\
\text { ratio } \\
\text { n: }\end{array}$} \\
\hline - Regular & 21 & 19.8 & 36 & 34.6 & 64 & 59.8 & 98 & 92.5 & 100 & $\begin{array}{c}94 . \\
3\end{array}$ & 98 & 92.5 \\
\hline - Irregular & 85 & 80.2 & 70 & 68,8 & 42 & 40 & 8 & 7.5 & 6 & 5.6 & 8 & 7.5 \\
\hline \multicolumn{7}{|c|}{$\mathrm{X} 2=1.08$} & \multicolumn{6}{|c|}{$\mathrm{P}$ value $=0.04 *$} \\
\hline \multicolumn{13}{|l|}{$\begin{array}{l}\checkmark \text { Breath } \\
\text { sound: }\end{array}$} \\
\hline - Clear & 31 & 29.2 & 33 & 31.1 & 69 & 64.5 & 97 & 91.5 & 100 & $\begin{array}{c}91 . \\
5\end{array}$ & 98 & 94.3 \\
\hline Wheezing & 75 & 70.8 & 73 & 68.9 & 37 & 35.5 & 9 & 8.5 & 6 & 5.6 & 8 & 7.5 \\
\hline \multicolumn{7}{|c|}{$\mathrm{X} 2=0.13$} & \multicolumn{6}{|c|}{$P$ value $=0.05$} \\
\hline
\end{tabular}


IMPACT OF AN EVIDENCE-BASED EDUCATIONAL etc...

Table (4): Percentage Distribution of the Pediatric Patient Post Operative weaning from Ventilator \& intensity of pain in PICU: $(n=106)$.

\begin{tabular}{|c|c|c|c|c|c|c|}
\hline \multirow{2}{*}{ Variable } & \multicolumn{4}{|c|}{ No } & \multicolumn{2}{|c|}{ Yes } \\
\hline & \multicolumn{2}{|c|}{ No. } & \multicolumn{2}{|c|}{$\%$} & No. & $\%$ \\
\hline \multicolumn{7}{|l|}{$\checkmark \quad$ Weaning from ventilator } \\
\hline - $\quad 1^{\text {st }}$ day & \multicolumn{2}{|c|}{106} & \multicolumn{2}{|c|}{$\mathbf{1 0 0 . 0}$} & 0 & 0.0 \\
\hline - $\quad 2^{\text {nd }}$ day & \multicolumn{2}{|c|}{34} & \multicolumn{2}{|c|}{32.1} & 72 & 67.9 \\
\hline - $\quad 3^{\text {rd }}$ day & \multicolumn{2}{|c|}{78} & \multicolumn{2}{|c|}{74.5} & 28 & 26.4 \\
\hline - $\quad 4^{\text {th }}$ day & \multicolumn{2}{|c|}{98} & \multicolumn{2}{|c|}{92.5} & 8 & 6.9 \\
\hline - $5^{\text {th }}$ day & \multicolumn{2}{|c|}{0} & \multicolumn{2}{|c|}{0.0} & 0 & 0.0 \\
\hline \multirow[t]{2}{*}{$\checkmark \quad$ Intensity of pain } & \multicolumn{2}{|c|}{$\begin{array}{l}\text { Mild } \\
(2-4)\end{array}$} & \multicolumn{2}{|c|}{$\begin{array}{c}\text { Moderate } \\
\text { (4-8) }\end{array}$} & \multicolumn{2}{|c|}{$\begin{array}{l}\text { Sever } \\
(8-10)\end{array}$} \\
\hline & No & $\%$ & No & $\%$ & No & $\%$ \\
\hline - $\quad 1^{\text {st }}$ day & 0 & 0 & - & - & 106 & $100 \%$ \\
\hline - $\quad 2^{\text {nd }}$ day & 77 & 72.6 & 23 & 22.5 & 6 & 5.7 \\
\hline - $\quad 3^{\text {rd }}$ day & 23 & 21.7 & 83 & 78.3 & 0 & 0.0 \\
\hline - $\quad 4^{\text {th }}$ day & 26 & 24.5 & 80 & 75.5 & 0 & 0.0 \\
\hline - $\quad 5^{\text {th }}$ day & 34 & 32.1 & 72 & 67.9 & 0 & 0.0 \\
\hline
\end{tabular}

Figure (3): Percentage Distribution for Pediatric Patient According to their post-operative Length of Stay at PCICU $(n=106)$.

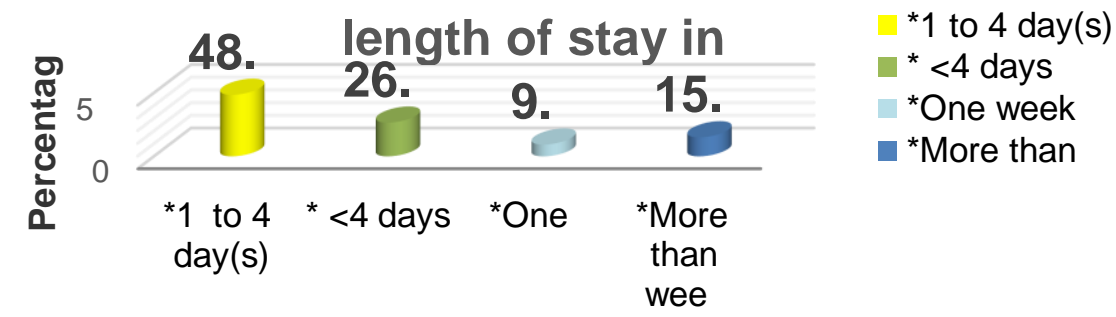

No. of

length of pediatric patients' stay at PCICU

Figure (4 ): Nurses Satisfaction in Care of Children with Open Heart Surgery according to their Total Satisfaction level at Pediatric Cardiology Unit

\section{nurses}

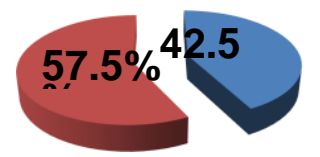

- satisfied

unsatisfie 


\begin{abstract}
Discussion
High quality nursing care for children in pediatric cardiology intensive care units (PCICU) demands specialized nursing knowledge and practical skills, due to its complexity and specificity. Nurses must be knowledgeable about physiological, behavioral, psychosocial and responses of the family that are extremely essential to understand, diagnose and treatment of the child with open heart surgery (Aiken et al. 2012\& Ball et al. 2018).
\end{abstract}

Nurses as the largest human resources element of health care systems and they have a major role in providing ongoing high quality care to patients (Whitman \& Allen, 2011 ). The implementation of the educational program designed on evidence based practices can to help pediatric nurses at cardiology unit to deal with, manage and care of children undergoing open heart surgery. Therefore, it's important to study the impact of an evidence-based educational program about pediatric open heart surgery care on both nurses and patient's outcomes.

Figure (1): as regards the studied nurses' years of experience working at cardiology intensive care units, this figure illustrated that, third $33 \%$ of nurses had from 1>3 years of working as a specialist at nursing care of cardiac pediatric patient. Arathy, 2011 indicated the advantages of nurses in young age group are being hyperactive which is always required in such crucial /vital wards and these findings disagreement with the results of the studies conducted by Ahmed and Hani (2017) who conducted a study about " Nurse's knowledge assessment and practice working hospitals at Governorate of Minia, reported that $85.5 \%$ of the studied nurses blow 26 years old with mean age $25.8 \pm 4.3$ years old, and 39\% of nurses had experience less than 5 years.

Education and training of studied nurses and years of experience in cardiology unit it is very important and essential to increase their awareness about care of children undergoing open heart surgery.

Education and training of studied nurses is essential to increase their awareness about care of children undergoing open heart surgery. Figure 2, In relation to nurses training, the findings of this study showed that, one quarter of the studied nurses just receive one course training program during working at the pediatric intensive care cardiology units (PCICU). This finding might due to lack of in-services education, continuous training and staff development in the study settings. This finding disagreement with the study of El -Sayed et al. ( 2018), who conducted a study about 'establishing basic standards of nursing care protocol at Intensive care unit" who reported that, most of nurses did not attend any previous in-service training program related to care at ICU. Additionally, Mosqueda-Pena et al. (2016), found that most of pediatric nurses hadn't had any training in developmental care.

On contrary Ezzat, ( 2015) who reported that the majority of studied nurses attended training courses. These was agree with Hafez (2014) \& Taha (2014) were revealed that nurses age and experience had an influence on nurses knowledge and practice improvement. In the same line, Dixon \& Crawford, (2012) and Tantawi et al. (2015). Reported that, all PCICUs have an induction and training programmers for new nursing staff to ensure that all nurses achieve a basic level of intensive care competence and can offer safe and effective care to the majority of ventilated children and young people on the unit. In my opinion, this may be due to lacking of nurses number, inability of 
IMPACT OF AN EVIDENCE-BASED EDUCATIONAL etc...

some nurses to attend training courses and lacking motivation.

According to Curtis \& White (2008), educational programs are important for refreshing and updating nurses' information. They may also play a role in retaining knowledge. It has been reported that knowledge retention generally falls to $75-89 \%$ of its original level after a relatively short 2-3 weeks' time. The current study tested the total level knowledge of the studied nurses about CHD, OHS and reported practices before/ immediately after and follow-up after 3 months of program implementation, through Table (2), and illustrated "poor" level of knowledge of the studied nurses before the program implementation, this percent improved in which the majority had 'high" level knowledge immediately the program implementation. While decreased after 3 months of the program implementation. This are parallel to the findings of Al-fatlawi \& Ahmed (2016). who stated that nurses" have poor knowledge before the educational program regarding and improved after the program. These results reflect the importance of education and continuous training on improving nurses' knowledge.

Concerning total nurses' practice according to CHD, OHS, Table (3), indicated that, the majority of the studied nurses had an incompetent practice score before conducting the program, while it improved to become competent practices immediately after the program and at follow up. The result is in harmony with Shaker, (2012) who mentioned that total nurse's practice regarding patient management was level score as they were unsatisfactory who reported that the total level of nurses' practice was high score. In contrast with Ali, (2016) \& Mohamed et al. (2014), agreed with this study that there is an unsatisfactory in patients practice. This finding disagreed with Ezzat, (2015) who revealed that most of studied sample had fair to low level of effective nursing practice. There is a highly statistical significant improvement in nurses' practice level after implementing the education in comparison with their practice level before the implementing of educational program.

Table (4): as regarding pediatric patient post operative weaning from ventilator \& intensity of pain in PCICU: $(n=106)$. Our study showed that, none of pediatric patient weaned from the ventilator at first day after operation (0.0 $\%)$ for each. Compared to more than two thirds $(67.9 \%)$ of them were weaned second day. Results was an agreement with Christopher et al. (2010), reported that, mechanical ventilation is often life saving but is associated with risks. Risks can be reduced by weaning and extubation as soon as the patient is able to support his/her breathing. Our study also showed, the occurrence of pain and its severity at the first and second days following operation. Numerous preceding studies have revealed that upsetting regarding longstanding pain is more stressful, complex to release, and distract Joshi et al. (2014), reported that, pediatric patient after operation are endangered via several sources of anxiety from both internal and external environment. Anxiety have an effect on their abilities to deal with their illness, social life and work, as a result make worse the pediatric patient psychological and physical state related to pain. Aziz \& Younis, 2013, reported that continuing studies, protocols for practices, and interventions for the management of pain. The patient education program includes training on how to access the system to request help. Most of pediatric patients are not aware of their pain intensity and are not able to report their pain. Patients should be taught how and when to express the intensity, quality, duration, and location of their pain. In my opinion, adequate management of acute 
pain doesn't only lead to a decrease in complications in the early period after surgery but may have long - term consequences in preventing pain. Although the intensity of acute pain does not always directly correlate with the intensity and incidence of long-term postoperative pain, it was suggest using preventative analgesia. For some time, pain has been described as the sixth vital sign and this reflects its importance in nursing assessment and patient care.

Figure (3) ), As regards to length of stay the pediatric patient in pediatric cardiology unit, the present study showed, approximately half of pediatric patient stay in PCICU from one to four days. These findings were matched with Arthur et al. (2010) who proved that, postoperative length of stay at PCICU was decrease to two or three days following postoperative interventions. The rationalization was mention by Herman et al. (2009) reported that, prolonged intensive care unit (PCICU) length of stay (LOS) following cardiothoracic surgery is a source of great expense to the health care system. Increased costs resulting from the consumption of excess PCICU resources emphasize the importance of being able to identify those patients at risk of experiencing prolonged LOS in advance of the planned intervention.

The current study figure (4), showed that, nurses satisfaction in care of child with open heart surgery in pediatric cardiology unit, more than half of nurses had " un satisfactory" in care of child with open heart surgery in PCICU, this result was supported by (Hippokraia, 2013) who stated that health care worker job satisfaction is a very important parameter that influences productivity as well as quality of work. Health care worker job satisfaction a great impact on qualities, efficiency and at the same time on costs of health care. Addition to Almojel, 2012 \& Ali et al. 2016 they stated that, in order to provide quality in health care; providing important services, respecting to standards of medical \& nursing ethics and patients rights in health care inevitable. Therefore, it can lead to promotion of health practice and attain balance division of liability between patients, doctors and nurses.

\section{Conclusion:}

Based on the findings of the current study, it is concluded that, the implementation of evidence-based educational program regarding care pre, immediate and at follow up children undergoing open heart surgery had a positive effect on the improvements of nurses' knowledge, performance and patients' outcomes. In addition, there were statistical significant differences between nurses' knowledge and performance pre immediate and follow up implementation were observed; all the areas were adequately performed by almost all nurses for almost all children in the study group. stated that health care worker job satisfaction is a very important parameter that influences productivity as well as quality of work.

\section{Recommendations:}

\section{For Nurses:}

- Regular and continuous educational and training programs should be applied for nurses to improve and update their knowledge and practice.

\section{For Mothers:}

- Good antenatal care (ANC) during pregnancy is important for the health of the mother and the development of the unborn baby. Good ANC during this time breaks a critical link in the continuum of care, and affects both women and babies.

- Education must begin with the mothers lchild family members at the first day of hospital admission about the open heart surgery to secure and help them to cope effectively with nurses and their children. 
III. For the hospital administrator

- Availability of the essential equipments and supplies necessary to implementation of nursing care.

- Assigning a suitable number of nurses at the PCICUs, that proportionates the children's undergoing open heart surgery number for successful implementation of the educational program.

Further studies are needed:

- Ongoing evaluation of educational program of open heart surgery is recommended to ensure that program content remains evidence-based.

- Replication of this study with a larger sample at different pediatric cardiac intensive care units and with longitudinal follow-up so that the results could be generalized and compared for differences between different countries.

Acknowledgements:

All the nurses who participated in the study in Mansoura university Hospital and Institute of Heart in Damietta, we would like to thank them for their help and cooperation during the study period and appreciate the great efforts of our supervisors in this work.

\section{References:}

1. Ahmed, S., M. \& Hani, M. (2017). Assessment of Nurse's Knowledge and Practice Working in District Hospitals at Minia Governorate about Neonatal Hyperbilirubinemia. IOSR Journal of Nursing and Health Science (IOSR-JNHS, 6(2).PP 09-16. Retrieved from, www.iosrjournals.org

2. Al-fatlawi, M. \& Ahmed, S. (2016). Assessment of Nurses' Knowledge Concerning Discharge Planning For Patients' With Open Heart Surgery in Cardiac Centre at Baghdad City. International Journal of Scientific and Research Publications, 6(10)
3. Ali A.O, Sleem W.F \&EL-Sayed R.S.(2016). Nurse's perception toward patient rights at Mansoura General Hospital, Master Thesis. P.67

4. Almoajel, A.(2012). Hospitalized patients' awareness of their rights in Saudi Governmental Hospital. Middle- east journal of scientific research, p.332-333

5. American Heart Association. (2015). How Can I Prepare for Heart Surgery available at https://www.heart.org/-/.../pe-abhhow-can-i-prepare-for-heart-surger...

6. American Heart Association. (2008). Heart and Stroke Statistical Update. Dallas, Tex: American Heart Association. https://www.ncbi.nlm.nih.go v/pubmed/18086926

7. Aiken, L. H., Sloane, D. M., Clarke, S., Poghosyan, L., Cho, E., You, L., ... \& Aungsuroch, Y. (2011). Importance of work environments on hospital outcomes in nine countries. Int $\mathbf{J}$ Qual Health Care, 23(4), 357-364.

8. Arathy, s. R. (2011). A study to assess the knowledge and practices among cardicac nurses about patients safety after cardiac catheterisation. Sree Chitra Tirunal Institute for Medical Sciences and Technology. Code No 6210, Available from: http://dspace.sctimst.ac.in/jspui/bitstr eam/123456789/1595/1/46 9. Pdf. [Accessed on 8th Jouly, 2017]

9. Azer S.Z., Eldeen S. M. A.,AbdELwahab, M. \&Ahmed A. M.(2011). Impact of the educational program among open heart surgery patients on minimizing the incidence of post operative infections. Journal of American science, 7 (6). P.82-84.

10. Aziz S. \& yonis S. (2013). Evaluation of Nurses' practices provided to the Patients who undergo 
Open Heart Surgery in Sulaimani center of Heart Diseases (S.C.H.D). Kufa Journal for Nursing Sciences 3 (1), PP. 60-80

11. Ball, J. E., Bruyneel, L., Aiken, L. H., Sermeus, W., Sloane, D. M., Rafferty, A. M., \& Griffiths, P. (2018). Post-operative mortality, missed care and nurse staffing in nine countries: A cross sectional study. International Journal Nurses Stud, 78, 10-15.

12. Cavalcante A., Brunori E., Lopes C., Silva A., Herdman H. (2014). Nursing diagnoses and interventions for a child after cardiac surgery in an intensive care unit. Journal of pediatric;86(1):100-159.

13. Christopher J. L. Newth, Venkataraman S., Douglas F. , Meert L., Harrison R. (2010). Weaning and extubation readiness in pediatric patients. Pediatric Critical Care Med. 2009 Jan; 10(1): 1-11. doi: 10.1097/PCC.0b013e318193724

14. Craven, R.F., Hirnle, C.J., \&Jensen, S. (2013). Fundamentals of nursing: human health and function 7th ed., Walters Kluwer health , Lippincott Williams \&Wilkins, Pp.542-562.

15. Curtis, J. R. \& White, D. B. (2008). Practical guidance for evidencebased ICU family conferences. Chest, 134, 835-843.

16. EL Sayed S.M., EL Feky H.A., Sultan MA, Abosaeda A.I. (2018). Critical care nurses' knowledge and practices regarding central venous line care bundle at emergency hospital Mansoura University p. 2035

17. Elsie A., and Marvin S. (2009). Children's National Medical Center's Congenital Heart Disease Screening Program, A Toolkit for Implementing Screening, 2th ed., Available at www.babysfirsttest.org/sites/default/f iles/CCHD\%20Toolkit.pdf

18. Ezzat N. (2015). Effect of implementing guidelines of nursing management of patients with chest tube drainage on nurse's knowledge and practice at Mansoura University Hospitals. Master Thesis, faculty of nursing, Mansoura University

19. Hawk B. M.(2013). Perioperative Care of the Pediatric Cardiac Patient Undergoing Noncardiac Surgery. 97 (6). AORN Journal. p.729-734. availability. http://dx.doi.org/10.1016/j.aorn.2013. 04.014

20. Hippokratia, Janicijevic1, Seke k., Djokovic A, and FilipovicT. (2015). Healthcare workers satisfaction and patient satisfaction where is the linkage? Advanced journal list, 17(2); PMC3743622 : p 157-162

21. Kurt R. Ann A., David Z. Isla O.( 2013). Pediatric heart surgery. available at http: umm.edu health medical ency articles pediatric heart surgery

22. Linde D.V., Konings E.M., Slager, M., Witsenburg, M. Willem A. (2011). Birth Prevalence of Congenital Heart Disease Worldwide, A Systematic Review and Meta-Analysis. Journal of the American College of Cardiology. 58

(21) November 2011DOI : 10.1016/j.jacc.2011.08.025

23. Michael D. Quartermain, Sara K. Pasquali, Kevin D. Hill, David J. Goldberg, James (2015). Variation in Prenatal Diagnosis of Congenital Heart Disease in Infants. Pediatrics;136; DOI: 10.1542/peds.2014-3783 originally published online July 27, 2015 (2).

24. Mohammed, S., Bayoumi, M., \& Mahmoud, F. (2014). The Effect of Developmentally Supportive Care 


Training Program on Nurses'
Performance and Behavioral
Responses of Newborn Infants.
Egypt: Pediatric Nursing-Faculty of
Nursing- Benha University.Journal of
Education and Practice, 5 (6).
Retrieved at,
http://www.bu.edu.eg/portal/uploads/
Nursing/Pediatric
25. Morsy A. (2000). Job satisfaction
among nurses and patients
satisfaction in Suez Canal University
Unpublished Master dissertation.
Faculty of Nursing. Suez Canal
University

26. Mosqueda -Pena, R., Lora-Pablos, D., Pavón-Muñoz, A., UretaVelasco, N., Moral-Pumarega, M. T., \& Pallás-Alonso, C. R. (2016). Impact of a developmental caretraining course on the knowledge and satisfaction of health care professionals in neonatal units: A multicenter study. Pediatrics \& Neonatology, 57(2), 97-104.

27. Neirotti R. A. (2013). Cardiac surgery: the infinite quest. Part III Pediatric cardiac surgery: a discipline on its own. Rev Bras Ciritical Cardiovascular ;28 (2): 248-252 DOI: 10.5935/1678-9741.20130035

28. Titler MG. ( 2011). Nursing Science and Evidence-Based Practice. Western Journal of Nursing Research , 33(3) 291- 295 Reprints and permission: http://www. sage pub. com/journals Permissions. nav DOI: $\quad 10.1177 / 0193945910388984$ http://wjn.sagepub.com 